\title{
Redes sociais como ferramenta de campanha em disputas subnacionais: análise do Twitter nas eleições para o governo do Paraná em 2010
}

\author{
Emerson Urizzi Cervi \\ Doutor em Ciência Política (Instituto Universitário de Pesquisa do Rio de Janeiro) \\ Professor na Universidade Federal do Paraná e na Universidade Estadual de Ponta Grossa \\ ecervij@gmail.com \\ Michele Goulart Massuchin \\ Mestranda em Ciência Política (Universidade Federal do Paraná) \\ mimassuchin@hotmail.com
}

\begin{abstract}
Resumo Este artigo tem por objetivo discutir o uso das redes sociais como ferramenta de campanha eleitoral, tendo como objeto de análise o conteúdo postado no Twitter pelos dois principais candidatos ao governo do Paraná - Beto Richa (PSDB) e Osmar Dias (PDT) - no período de $1^{\circ}$ de julho a 3 de outubro de 2010. Procura-se, por meio de algumas características (número de postagens, temática, discurso, tipo dos post, uso de links, presença de adversários, entre outras), identificar como os candidatos utilizaram o suporte tecnológico em estratégias políticas de contato com os eleitores. A metodologia utilizada é quantitativa de análise de conteúdo e permite ainda comparar os dados entre os dois candidatos, que, juntos, somaram 3.165 postagens. Com isso, torna-se possível identificar diferenças na utilização do Twitter entre os dois principais concorrentes ao governo do Paraná em 2010.
\end{abstract}

Palavras-chave: redes sociais, campanha eleitoral, Twitter, eleições.

\section{Introdução}

$\mathrm{O}$ Artigo discute o emprego das redes sociais em períodos eleitorais como mecanismo usado pelos candidatos para se aproximar dos eleitores - pelo menos daqueles que têm acesso às plataformas digitais de comunicação. Para tanto, estudam-se as postagens feitas no microblog Twitter pelos dois principais concorrentes ao governo do estado do Paraná - Beto Richa (PSDB) e Osmar Dias (PDT). O objetivo é comparar as quantidades e as características (qualidades) das mensagens escritas em nome dos candidatos, assim como identificar o perfil predominante, no uso do Twitter, pelos dois principais concorrentes ao governo do Paraná.

Para a produção da pesquisa, utiliza-se a metodologia quantitativa de análise de conteúdo, com informações referentes ao número de mensagens escritas, aos temas abordados, ao discurso utilizado, à citação de adversários, à presença de elementos que citem a campanha, partido ou coligação e ao tipo de postagem (retweet, resposta e publicação). A análise dessas informações permite identificar semelhan- 
ças e divergências entre os candidatos, possibilitando apontar alguns padrões de uso do Twitter por eles. Os dois concorrentes foram escolhidos para este estudo de caso por terem, juntos, somado $98,07 \%$ dos votos válidos na eleição de 2010. Já considerando o uso de redes sociais, em relação aos tweets, ao todo, eles postaram 3.165 mensagens no microblog.

Ressalte-se que, embora a internet ainda seja um veículo de acesso limitado para vários segmentos sociais, se comparado aos veículos tradicionais, torna-se necessária uma caracterização deste espaço como local de debate utilizado pelos candidatos para manter contato com líderes de opinião, militantes partidários e eleitores. $\mathrm{O}$ estudo de caso proposto aqui não pretende apresentar modelos explicativos gerais, mas indicar caminhos para a análise empírica das novas plataformas de debate político-eleitoral. Mesmo não havendo indicativo de que seja capaz de interferir na mudança ou na manutenção de votos, a internet permite uma interação da elite política com os usuários, podendo ampliar o debate eleitoral, principalmente por meio das redes sociais. Assim, o objetivo deste texto não é discutir o impacto do Twitter na decisão do voto, mas de que forma os candidatos o utilizam como ferramenta a serviço da comunicação política em períodos eleitorais.

O próximo tópico do texto apresenta a discussão sobre o uso da internet nas campanhas eleitorais no caso brasileiro, apontando para o papel das redes sociais nas disputas. Depois se aliam os dados referentes ao uso do microblog pelos candidatos Beto Richa (PSDB) e Osmar Dias (PDT). Em seguida são feitas considerações finais.

\section{Internet como suporte para campanhas políticas}

O desenvolvimento da comunicação política é influenciado pela modernização tecnológica, econômica e política que envolve os partidos, a mídia e os próprios eleitores (Norris, 2001). Nas democracias contemporâneas, as campanhas passaram por um processo de profissionalização até chegar ao estágio pós-moderno, datado do início da década de 1990 (Norris, 2004). Uma das principais novidades desta fase é o uso de tecnologias como estratégia de campanha eleitoral pelos partidos, aumentando a quantidade de informação política que circula na sociedade durante o período eleitoral e possibilitando mecanismos potencialmente mais democráticos de debate horizontalizado e amplo. Embora no Brasil o uso da internet como estratégia de comunicação política seja recente, tendo indícios mais significativos apenas nas eleições de 2002 (Aldé, 2004), em outros países, como nos EUA, sua utilização nas campanhas teve início ainda na década de 1990 e já existe uma série de estudos empíricos sobre a utilização de sites, blogs e redes sociais em campanhas (Gibson e Ward, 2000).

Estudos recentes nessa área têm demonstrado que os partidos e candidatos passaram a se organizar na internet com o objetivo de aproximar os militantes e difundir informações políticas (Vaccari, 2008). Embora esse espaço não seja o principal meio informativo usado pelos eleitores (Coutinho e Safatle, 2009), ele contribui para compor o ambiente informacional e dar visibilidade pública aos candidatos e aos partidos. A nova mídia tende a ser considerada como um complemento da campanha eleitoral feita em outras esferas (Anduiza, 2009; Dahlgren, 2000), além de possibilitar mais participação política dos eleitores nos acontecimentos políticos (Norris, 2001).

Outro conjunto de pesquisas indicam as maneiras como os novos meios têm contribuído para aumentar a participação política (Stanley e Weare, 2003; Davis, 1999), além de diminuir a distância entre os eleitos e a sociedade civil (Coleman, 1999) e potencializar a circulação de informação política na sociedade. No Brasil, as pesquisas tornaram-se mais efetivas nos últimos anos, tratando principalmente do uso de mecanismos de participação (Iasulaitis, 2007; Nicolás, França e Braga, 2010). No entanto, deve-se ressaltar que, diferentemente dos EUA e de países europeus, no Brasil o processo de modernização da comunicação política com a internet ainda é recente e encontra-se em desenvolvimento.

Acompanhando este processo mais tardio, há dois fatores discutidos na literatura que interferem no uso das ferramentas digitais: a cultura política e a acessibilidade. Segundo Levy (1999), a distribuição desigual de competências técnicas - alguns têm mais acesso do que outros - resulta em desigualdade de acesso às informações. Mas, para além do acesso, a noção de cultura cívica aponta para características do mundo sociocultural que constituem condições prévias de participação democrática (Dahlgren, 2000). Portanto, como aponta Montero (2009), são necessárias mudanças na cultura política e na concepção de democracia, pois a internet não vai modificar práticas já cristalizadas na sociedade, mas é a cultura política que define o grau de democratização efetiva a partir das novas tecnologias (Coleman, 1999).

Mesmo que a acessibilidade não tenha relação direta com o consumo de informações políticas neste espaço, o aumento da penetração da rede no Brasil já demonstra alguns avanços. Análises realizadas por institutos de pesquisas têm mostrado que o número de acessos no país em 2010 era maior que em anos anteriores (NIC/BR, 2010). Além disso, trabalhos sobre as eleições de 2010, embora tenham eviden- 
ciado baixa qualidade do debate nos websites, destacaram índices significativos de candidatos e partidos utilizando ferramentas da internet (Iasulaitis, 2007; Nicolás, França e Braga, 2010), o que tende a contribuir para o crescimento do número de eleitores conectados.

Além dos fatores contextuais que devem ser considerados, é necessário destacar alcances efetivos das novas tecnologias para a democratização do debate eleitoral. Segundo Norris (2001; 2003), a atenção dispensada para as mensagens das novas mídias está associada aos níveis de conhecimento político e serve para reforçar as predisposições partidárias, atingindo principalmente os que já manifestam interesse por política. Isso significa que o acesso e a participação on-line são dados àqueles que já apresentam engajamento político na esfera tradicional de discussão. No entanto, para Turiera-Puigbó (2009), isso não impediria um maior alcance das mensagens, pois, segundo a autora, os indivíduos que acessam o conteúdo político presente na internet, por terem essa predisposição para a militância, podem fazer com que o alcance das mensagens disponibilizadas na rede aumente para além daqueles que as acessam diretamente. A internet também representa um espaço de debate e de distribuição de informações que independe dos meios de comunicação tradicionais (Anduiza, 2009). Dessa forma, os estudos que acompanham a utilização da internet pelos políticos durante as eleições partem do pressuposto de que os novos meios têm impacto potencial no debate como um todo e um impacto efetivo para um conjunto reduzido de participantes - aqueles que já apresentam posições políticas predeterminadas e anteriores ao período eleitoral. As mensagens publicadas não ficam restritas apenas ao ambiente on-line, ou seja, a presença de websites contribui para aumentar a circulação de informações sobre política na esfera pública e a visibilidade pública de atores políticos, aproximando os candidatos de seus eleitores. Sem contar o fato de que não é possível separar completamente os efeitos das novas mídias em relação aos meios tradicionais, visto que os conteúdos e os atores perpassam as fronteiras do tradicional e do novo no que diz respeito à comunicação eleitoral.

\section{O papel das redes sociais em disputas eleitorais}

Neste artigo, partimos do pressuposto de que existe um "ambiente informacional" multidirecional, complexo e com níveis distintos de controle que fornece um conjunto de informações de diferentes fontes que se conectam informalmente através dos receptores/eleitores, provocando um efeito de interagendamento entre elite política, eleitores, mídia tradicional e novos meios. Assim, dentro do "ambiente informacional" mais amplo, consideramos que blogs pessoais são apropriados como ferramenta de representação política por apresentarem baixo custo de produção e relativa capacidade de distribuição da informação, aliados à possibilidade de atingir um grande público num curto período de tempo (Gomes, 2005). A interação política é uma forma de fazer aumentar o poder simbólico e material do público, além de demonstrar convicção, posições e vontade de participar dos negócios públicos (Gomes, 2005). No caso do objeto de estudo em questão, ainda é possível que o leitor interaja diretamente com o candidato. A conversação aberta e livre é a base para a ação política, o que pode ser encontrado de maneira mais completa nas redes sociais eletrônicas do que nos meios massivos. Além disso, nas eleições de 2010, muitos candidatos passaram a utilizar sites, blogs e redes sociais após a regulamentação por lei federal, que em 2009 alterou a legislação eleitoral.

Uma das ferramentas recentes que melhor sistematiza esse processo de interação e participação política nas novas mídias é o microblog Twitter, tanto que, nas eleições de 2010, ele foi objeto de atenção de diversos candidatos para manter contatos permanentes com parte dos eleitores. Mesmo não sendo possível apenas a partir da análise de conteúdo identificar os impactos diretos para a decisão do voto, as redes sociais, por exemplo, tornaram-se espaço de debate, pois as discussões que ocorreram nesses meios alternativos ganharam espaço na mídia tradicional, seja como fonte para os jornalistas ou para ampliar o debate a um número maior de eleitores, de forma indireta, ou a partir de um interagendamento.

O Twitter é uma variante dos blogs que apresenta limitação do conteúdo e se constitui como rede social porque os usuários dispõem de um espaço próprio e uma lista de contatos para interagir (Recuero, 2009; Orihuela, 2007). A ferramenta foi criada em 2006 e disponibilizada na rede mundial de computadores pela empresa norte-americana Obvious, tendo como proposta inicial que as pessoas postassem o que estivessem fazendo. Entretanto, logo em seguida começou a ser usado para as mais diversas finalidades, desde postagens de questões banais até informações de interesse público. Segundo Lemos (2009), esse processo permite uma conversação, por meio dos mecanismos de resposta, possibilitando maior interação e uma alternativa aos meios massivos. Além desse processo conversacional entre os usuários, o Twitter possibilita uma instantaneidade que o difere de outras mídias (Lemos, 2009). De acordo com Orihuela (2007), os perfis das postagens podem ser: a) trivialidades cotidianas; b) conversas em pequenas comuni- 
dades; c) compartilhamento de informação e endereços de sites, e d) difusão de notícias e opiniões. Sobre os usos da ferramenta, Recuero (2009) aponta para uma grande tendência entre os usuários em favor da publicação de informações, embora ela também seja usada para a conversação, como vamos observar nos dados analisados. No caso de campanhas eleitorais, os dois últimos usos são os mais intensos - difusão de informações sobre os candidatos e conversação com leitores/seguidores.

Tratando-se especificamente do uso do Twitter pela elite política, essa ferramenta é a versão on-line da relação corpo a corpo que os candidatos exercitam na disputa política (Spyer, 2009). A expansão da internet e de suas ferramentas permitiu que os eleitores passassem a ter maior proximidade com candidatos e eleitos, o que possibilita fiscalizar o poder público, acompanhar o governo, entre outras ações. "O Twitter vem se tornando uma maneira de aproximar administradores públicos e cidadãos" (Spyer, 2009 , p.69). No entanto, este espaço apenas complementa as demais esferas de disputa e de visibilidade pública, sendo uma estratégia dos candidatos para se aproximar de seus eleitores. Para testar essas afirmações identificadas na literatura da área sobre o uso do Twitter em campanhas eleitorais, a seguir faz-se uma análise do uso do microblog pelos dois principais candidatos ao governo do Paraná em 2010. ${ }^{1}$

Para o estudo do uso do microblog Twitter como ferramenta de campanha pelos candidatos ao governo do estado do Paraná proposto aqui, utiliza-se a metodologia quantitativa de análise de conteúdo para identificar as características das postagens. A coleta dos dados é feita com base em variáveis que representam características quantitativas e qualitativas do conteúdo das mensagens escritas pelos dois candidatos. Este artigo apresenta o número de postagem, temática das postagens, forma do discurso, tipo de post, presença de adversários, presença e tipos de links e presença de campanha para partidos ou coligação, apontando a distribuição dessas características ao longo dos quatro meses de campanha - de $1^{\circ}$ de julho a 3 de outubro de 2010. Os primeiros dados (Tabela 1) mostram a diferença entre os dois candidatos quanto ao número de postagens de cada um e à distribuição delas ao longo do período.

Os dados sobre a quantidade total de mensagem mostram que, enquanto Beto Richa (PSDB) exibiu 937 postagens, o candidato Osmar Dias (PDT) apresentou mais que o dobro do seu adversário, com 2.228 postagens. No total, o primeiro representou
29,6\% do total dos dois, enquanto Osmar Dias ficou com $70,40 \%$, o que é uma diferença bastante significativa. Considerando o período da análise, em média eles publicaram, juntos, mais de 35 tweets por dia, dos quais, ainda em termos médios, Osmar Dias era responsável por 24 e Beto Richa por 11 tweets. $^{2}$ Portanto, a primeira diferença entre os dois diz respeito à frequência com que utilizaram a ferramenta. Mas é preciso ainda identificar como foi o uso ao longo do tempo, para identificar alterações no número de postagens.

Tabela 1 - Quantidade de posts e distribuição ao longo do tempo

\begin{tabular}{|c|c|c|c|c|}
\hline \multirow{2}{*}{ Semana } & \multicolumn{2}{|c|}{ Beto Richa } & \multicolumn{2}{c|}{ Osmar Dias } \\
\cline { 2 - 5 } & $\mathbf{N}$ & $\%$ & $\mathbf{N}$ & $\%$ \\
\hline 1 (julho) & 57 & 6,1 & 238 & 10,7 \\
\hline 2 & 62 & 6,6 & 337 & 15,1 \\
\hline 3 & 58 & 6,2 & 145 & 6,5 \\
\hline 4 & 68 & 7,3 & 176 & 7,9 \\
\hline 5 (agosto) & 64 & 6,8 & 167 & 7,5 \\
\hline 6 & 53 & 5,7 & 113 & 5,1 \\
\hline 7 & 52 & 5,5 & 88 & 3,9 \\
\hline 8 & 45 & 4,8 & 140 & 6,3 \\
\hline 9 & 79 & 8,4 & 201 & 9,0 \\
\hline 10 (setembro) & 106 & 11,3 & 200 & 9,0 \\
\hline 11 & 119 & 12,7 & 160 & 7,2 \\
\hline 12 & 68 & 7,3 & 123 & 5,5 \\
\hline 13 & 106 & 11,3 & 140 & 6,3 \\
\hline Total & 937 & 100,0 & 2228 & 100,0 \\
\hline \% Candidato & 937 & 29,6 & 2228 & 70,4 \\
\hline Fonte: Autores & & & &
\end{tabular}

Observando a tabela, constata-se que Beto Richa (PSDB) iniciou a campanha com um número menor de postagens no Twitter do que no final do período. Enquanto as primeiras semanas representam pouco mais de $6 \%$ do total de postagens, as últimas chegaram a um percentual de $12,7 \%$, o que significa que o número de postagens dobrou entre o início e o final da campanha, ou seja, com o passar do tempo, o candidato utilizou mais a ferramenta. Mesmo tendo um número menor no total de postagens. Já para Osmar Dias (PDT), identifica-se uma relação oposta, com queda ao longo das semanas. No início, o percentual de postagem foi de $10,7 \%$ e $15,1 \%$, respectivamente nas duas primeiras semanas. No entanto, na décima segunda e décima terceira semanas os percentuais foram de apenas $5,5 \%$ e $6,3 \%$. Ou seja, mesmo com

1. O resultado da eleição de 2010 para o governo do Paraná foi vitória no primeiro turno para o candidato do PSDB, Beto Richa, com $52,44 \%$ (3,03 milhões) de votos válidos, contra 45,6\% (2,64 milhões) de Osmar Dias (PDT). Fonte: TRE-PR.

2. Ambos os candidatos tiveram assessorias especializadas em produção de conteúdo para redes digitais em suas estruturas de campanha, portanto, não estamos considerando que os tweets foram escritos pelos próprios, mas sim pelas estruturas de campanha deles. 
um número maior de postagens, a tendência foi de queda com a aproximação da data da eleição. Mas, da mesma forma que nos dados referentes a Beto Richa, o período intermediário também apresentou baixos percentuais em relação ao início e ao fim de campanha, sendo neste caso de $5,1 \%, 3,9 \%$ e $6,3 \%$ para as semanas 6,7 e 8 . Nesse período, os dois candidatos apresentaram uma distribuição parecida de percentuais das postagens. Para ilustrar, o gráfico abaixo indica a variação ao longo do tempo. Percebe-se como há uma inversão entre os candidatos, se comparados os dados das primeiras e últimas semanas, assim como também um momento - entre as semanas 3 e 8 - em que os percentuais são próximos.

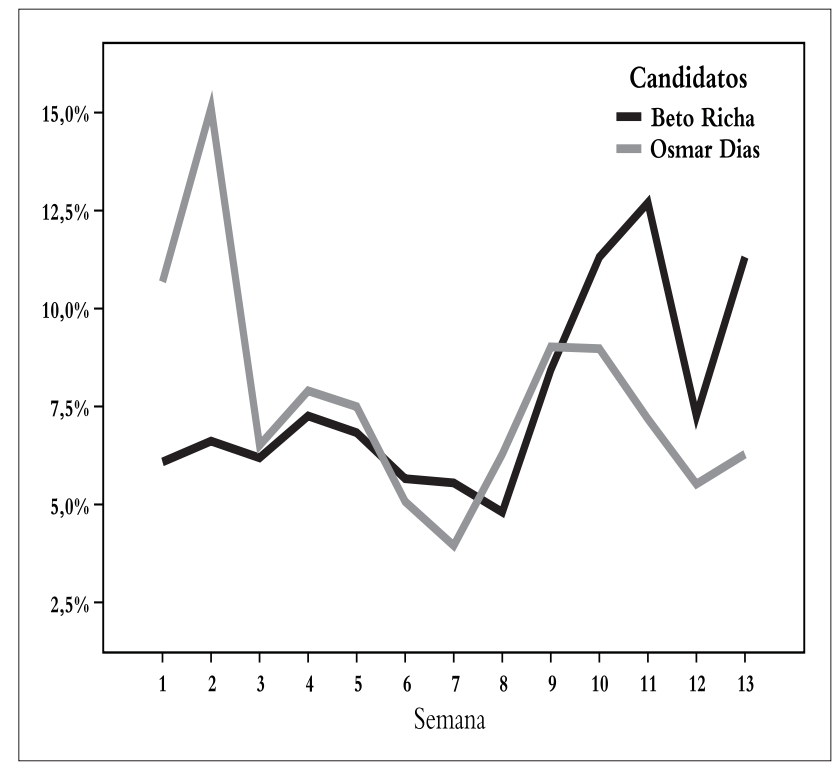

Gráfico 1 - Distribuição percentual de tweets por semana Fonte: Autores
Embora se destaque o maior uso do Twitter por Osmar Dias em comparação com Beto Richa, salienta-se que a quantidade de postagens de ambos durante o período é maior do que em outras disputas. Agio (2011) analisou os dados das eleições presidenciais, mostrando como os candidatos se apropriaram dessa ferramenta. No entanto, no período de agosto a setembro, foram apenas 71 postagens da candidata Dilma Rousseff, 501 de José Serra e 748 de Marina Silva. Ou seja, há uma diferença, em termos quantitativos, do uso do Twitter nas eleições presidenciais se comparado com as eleições para governador no Paraná.

Esses instrumentos alternativos de debate, entre os quais se encaixam as redes sociais, podem ser usados por candidatos em diversas situações, como no caso daqueles que não dispõem de muito espaço nas mídias tradicionais, a exemplo do candidato Plínio Arruda Sampaio (PSOL), que usou a comunicação do Twitter para conquistar espaço nas mídias tradicionais (Agio, 2011) a partir da visibilidade que obteve. Ou também quando precisam mobilizar eleitores, usando todos os meios possíveis para agregar votos, como foi o caso de Marina Silva (Agio, 2011), que pretendia disputar o segundo turno.

No caso do Paraná, os dois candidatos mantiveram-se próximos nas preferências eleitorais durante o período, muito à frente dos demais adversários. Dados sobre a intenções de voto dos eleitores coletados no final de julho mostram Beto e Osmar tecnicamente empatados (43\% e 38\%, respectivamente), enquanto Paulo Salamuni (PV) tem 1\% dos votos e os demais candidatos não chegam nem a $1 \%$. Isso pode ajudar a explicar o grande número de postagens, já que em diversas pesquisas os dois candidatos mantiveram-se

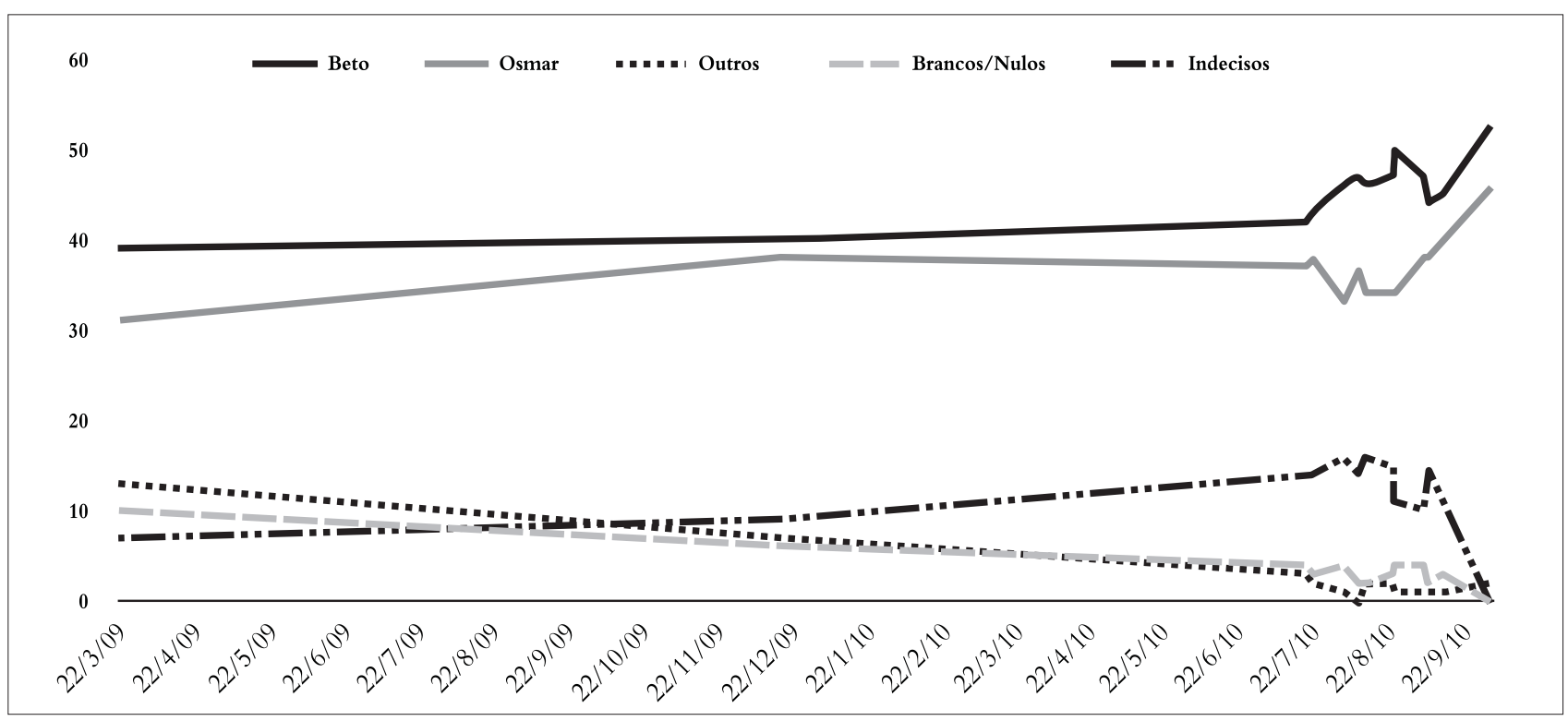

Gráfico 2 - Distribuição da intenção de voto no período pré-eleitoral e da campanha

Fonte: relatórios de pesquisa dos institutos Datafolha/Ibope/VoxPopuli 
tecnicamente empatados. Em outras palavras, pela nossa hipótese, a intensificação do uso de redes sociais estaria diretamente relacionada ao grau de competitividade da disputa.

A liderança, ao longo de todo período, foi de Beto Richa. Percebe-se que, no período pré-eleitoral, Beto Richa apresenta estabilidade nas preferências dos eleitores, enquanto Osmar Dias cresce de 30\% a $40 \%$ nas intenções de voto. No começo da campanha, no segundo semestre de 2010, o candidato do PSDB sobe nas pesquisas, ao passo que Osmar apresenta uma leve queda, sendo que mais para o final há uma manutenção dos votos em Beto Richa, mas cresce a intenção de voto para Osmar. Comparando essas informações com o gráfico que mostra o comportamento deles no Twitter, identifica-se que Beto Richa passou a postar mais quando seu adversário chegava mais próximo em termos de percentual de votos nas pesquisas. Ao contrário de Osmar que, nesse período - em que cresceu -, diminuiu as postagens. A movimentação maior no Twitter de Osmar foi durante o início da campanha, quando ele apresentava percentuais mais baixos nas pesquisas e precisava pedir votos, como exemplifica as postagens: "Pode deixar. Vou começar pedindo também o seu voto" (17/julho - Osmar Dias) e "Analise bem as nossas propostas. Acredito que vc se surpreenderá positivamente" (23/ julho - Osmar Dias).

Destaca-se que isso não significa que foi a mobilização do Twitter que causou o aumento das intenções de voto no candidato, mas sim que a rede foi usada para mobilizar os líderes de opinião e se apresentar 'publicamente' aos eleitores, mostrando suas propostas de políticas, suas informações de campanha, entre outros assuntos, como mostram os seguintes posts: "Durante a visita à Nutrilatina falei do meu compromisso de construir mais creches no Estado" (21/julho - Osmar Dias) e "Conto com todos na largada da campanha q faremos terça com o @joseserra_na Rua XV.Concentração 12 h na Santos Andrade" (4/julho - Osmar Dia). Por meio destes exemplos, é possível perceber que o Twitter foi usado para contar a rotina dos candidatos, mostrar as propostas e chamar os eleitores para contribuir com a campanha. Também foi usado como forma de mostrar que estavam em ação e fazendo campanha, como no exemplo: "Sigo p/encontro c/prefeitos de toda região. Agenda muito produtiva e um ótimo sábado de sol em Londrina" (3 de julho - Beto Richa).

No Twitter é possível publicar posts próprios, replicar (retweetar) mensagens escritas por outros indivíduos ou responder aos questionamentos feitos diretamente no seu perfil. Esses são mecanismos oferecidos pelo microblog e representam potencialidades interativas. Por meio da pesquisa, é possível identificar como elas são usadas pelos candidatos para interagir com seus eleitores. As respostas demonstram o interesse dos candidatos em manter contato com os eleitores, sendo que o processo de replicar mensagens de terceiros possibilita maior circulação de algumas informações pelas quais as pessoas manifestam interesse.

Tabela 2 - Tipo de postagem feita pelos candidatos

\begin{tabular}{|l|c|c|c|c|c|}
\hline \multirow{2}{*}{ Tipo de post } & \multicolumn{2}{|c|}{ Beto Richa } & \multicolumn{2}{c|}{ Osmar Dias } & $\begin{array}{c}\text { Dif. \% } \\
\text { (Beto-Osmar) }\end{array}$ \\
\cline { 2 - 6 } & $\mathbf{N}$ & $\%$ & $\mathbf{N}$ & $\%$ & \\
\hline Resposta & 532 & 56,7 & 935 & 40,8 & $+15,9$ \\
\hline Retweet & 47 & 5,0 & 232 & 19,4 & $-14,4$ \\
\hline Publicação & 358 & 38,3 & 1061 & 39,9 & $-1,6$ \\
\hline Total & 937 & 100 & 2228 & 100 & \\
\hline
\end{tabular}

Fonte: Autores

Com base nesses dados, é possível identificar algumas similaridades e divergências entre os candidatos. As postagens de Beto Richa (PSDB) foram mais centradas nas respostas ao usuário, indicando ampla relação com os eleitores, o que geralmente se dá a partir de perguntas sobre políticas de governo, propostas para temas específicos, elogios, desejos de boa sorte, entre outros casos. O candidato apresentou $56,7 \%$ das suas postagens como respostas específicas aos usuários, o que representou 15,9 pontos percentuais acima de Osmar Dias. No entanto, não é possível concluir, apenas com estes dados, sobre quem foi mais interativo com seus eleitores, pois a resposta do candidato só se dá a partir do momento em que os seguidores perguntam algo diretamente para ele. $\mathrm{Ou}$ seja, ele pode ter um maior percentual nessa categoria, pois seus eleitores interagem mais que os eleitores de Osmar Dias, o que o 'estimula' a responder mais as questões propostas pelos seguidores. Sendo assim, a interação entre eleitores e candidatos a partir de diálogos próprios não depende da iniciativa apenas do candidato, mas do eleitor em questionar sobre os temas de interesse público ou fazer menção direta ao candidato. Em resumo, Beto respondeu mais e retweetou menos que Osmar, em termos proporcionais.

A possibilidade de republicar a mesma notícia de outro membro da rede não foi muito usada pelo candidato do PSDB, sendo apenas 5\% dos posts e menos 14,5 pontos percentuais em relação a Osmar Dias. Destaca-se que esse mecanismo foi mais utilizado pelo candidato para destacar informações positivas enviadas por eleitores. A publicação própria do candidato, voltada para todos os seus seguidores, representou $38,3 \%$ do total, com apenas 1,6 ponto percentual abaixo de Osmar Dias.

Já Osmar Dias (PTB) tem percentuais próximos a 40\% nas categorias de resposta e publicação de informação; na categoria republicar informações de terceiros, esse índice foi $19,4 \%$ do total. Isso mostra uma pequena diferença entre os candidatos, pois, en- 
quanto Beto está mais centrado nas respostas, Osmar responde, mas ao mesmo tempo posta informações próprias. Isso indica que, para eles, o Twitter pode apresentar funções diferentes: ao passo que Beto Richa apresentou mais postagens voltadas para responder usuários, Osmar Dias se manteve dividido entre responder e produzir informações próprias.

Para complementar esta análise, observa-se a distribuição do tipo de post durante o período para os dois candidatos. O Gráfico 3 representa o uso feito por Beto Richa (PSDB) e Osmar Dias (PDT). No caso do candidato tucano, percebe-se que os posts que republicam mensagens de outras pessoas aparecem muito pouco durante quase todo o período, exceto na última semana, quando o candidato retweeta informações positivas sobre ele e mensagens de apoio, como estas postadas no dia 27 de setembro: "Bom dia, força para esta semana que consolidará o Novo Paraná" e "Contagem regressiva para a vitória de @ BetoRicha”. Já as postagens que contêm respostas ou notícias próprias aparecem de maneira oposta no final e no começo da campanha: quando ele responde, deixa de postar mensagens próprias, mas destaca-se que, em alguns momentos, como na segunda e na décima semanas, as respostas chegaram a um número bastante alto de postagens, alcançando 50 e 80 posts, respectivamente. Nota-se ainda que, nas últimas duas semanas, o candidato respondeu menos, substituindo as respostas por publicação própria de notícias e retweets.

Já os dados de Osmar Dias mostram um comportamento diferente, tendo percentuais mais altos para resposta e publicação de informação, mas com períodos em que um tipo se sobrepõe a outro. A publicação de notícias apresenta queda até o meio do período e volta a subir até o final da campanha, ou seja, aumenta consideravelmente até o final da campanha, tomando espaço da republicação e também das respostas. Estas últimas apresentaram tendência de queda durante quase toda a campanha. Comparando as distribuições dos dois candidatos, observa-se que o uso da rede oscilou mais para Osmar Dias do que para Beto Richa.

Observa-se que, se comparado com Beto Richa, Osmar Dias apresenta mais republicação de material, inclusive com aumento até a nona semana e depois com uma queda acentuada. Nesse período de aumento, apareceram mensagens de apoio ao candidato, como esta do dia 5 de setembro "O Povo do Paraná tá vendo que Compromisso, PALAVRA, Competência e seriedade é com @Osmar_Dias12 \#VamosPR". Também apareceram mensagens com críticas e de enfrentamento, como estas postadas no dia 4 de setembro e 18 de agosto: "Temos um mês ainda Tucanos... E já estamos sabendo que @Osmar_ Dias12 cresceu nas pesquisas... que bodocadaaaa" e "Quem ajudou a colocar o segundo maior pedagio do PR em Jataizinho, prejudicando o norte do PR, diz que vai baixar, mentira". Esses exemplos mostram que Osmar aproveitava as postagens de terceiros para atacar o adversário.

Além do número e das tendências de postagens ao longo do tempo, também é possível identificar a temática presente nas postagens feitas pelos candidatos. Para a análise, os temas foram agregados da seguinte forma: "Campanha", que são textos basicamente informativos, que tratam da agenda do candidato; "Assuntos pessoais", que definem posts em que o candidato não fala de temas de interesse público, mas de questões familiares, de amigos e entretenimento; "Propostas de políticas públicas", que engloba postagens que se referem a ações e propostas futuras; "Apoio", que caracteriza textos em que o candidato pede apoio aos eleitores; "Ético-moral", que define assuntos relacionados a valores, problemas com a justiça etc.; "Novas mídias", que trata de discussões sobre o uso de novas mídias

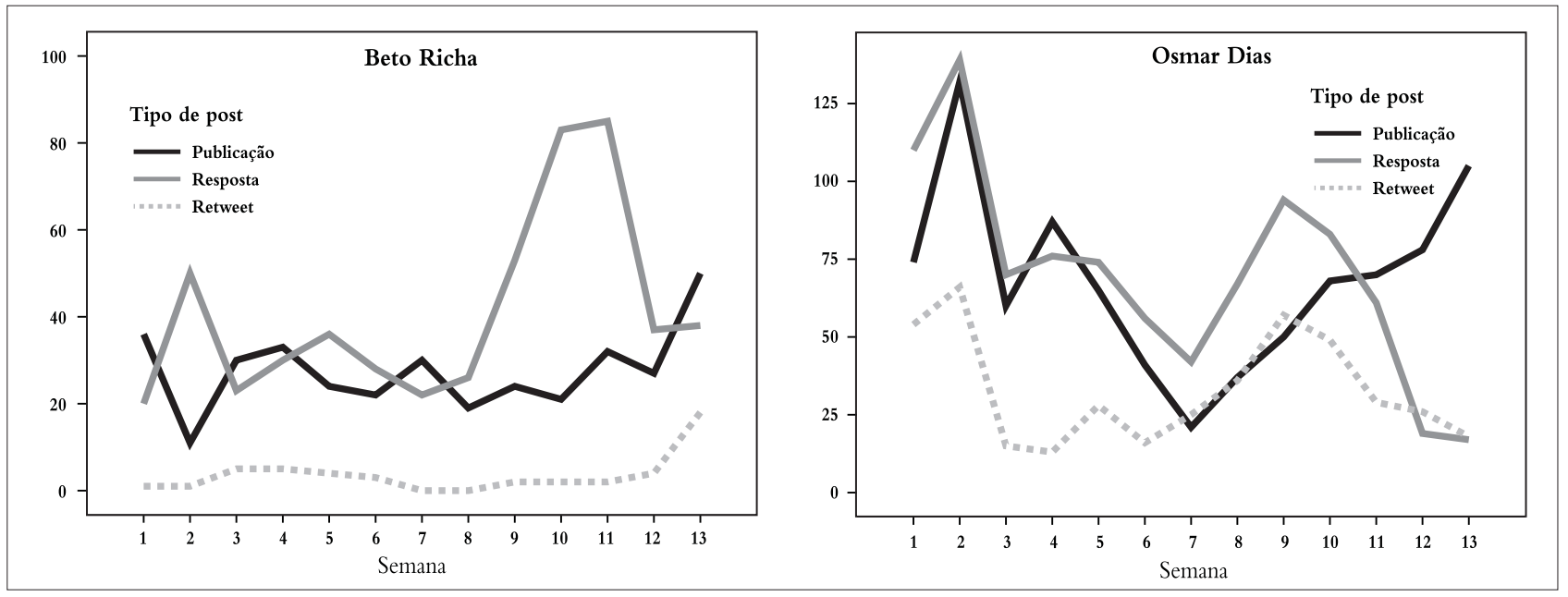

Gráfico 3 - Distribuição por tipo de postagem de Beto Richa (esq.) e Osmar Dias (dir.) 
- Twitter, Twitcam, sites e blogs - na campanha, e "Conversa e agradecimentos", que categorizam postagens em que o candidato agradece seus seguidores ou fala diretamente com eles.

Os que mais aparecem nas mensagens do Beto Richa são "Campanha", com 44,9\%; "Propostas de políticas públicas", com 24,4\%, e "Assuntos pessoais", com 10,4\%. Os demais aparecem com menores percentuais, o que mostra uma centralidade nos temas propostos pelo candidato nas redes sociais. Já no caso do candidato Osmar Dias os maiores destaques são para "Campanha", com 36,3\%; "Propostas de políticas públicas", com 16,3\%, e "Conversa e agradecimento", com 14,7\%. Embora os percentuais sejam próximos para os dois candidatos, "Assuntos pessoais" não é o terceiro item que mais aparece para o candidato do PDT. Essa é a principal diferença entre os dois.

Mas, de modo geral, o foco dos candidatos é o material informativo de campanha, principalmente de agenda, o mais predominante nesse tipo de postagem, como mostram os exemplos: "A caminho de Porto Rico sol c/ algumas nuvens mas todos muito animados c/visita do@joseserra_na regiao noroeste" (23/julho - Beto Richa) e "Estou em Cascavel, onde faço daqui a pouco uma caminhada do calçadão. Depois estarei na TV Tarobá e à noite participo de comício" (21/setembro - Osmar Dias). Isso mostra que o foco dos candidatos, quanto ao tema das suas postagens, era basicamente informar o leitor, atuando como um meio alternativo informacional, embora questões pessoais tenham ocupado percentuais consideráveis para ambos.

Tabela 3 - Distribuição dos temas por candidatos

\begin{tabular}{|l|r|r|r|r|}
\hline \multirow{2}{*}{ Tema } & \multicolumn{2}{|c|}{ Beto Richa } & \multicolumn{2}{c|}{ Osmar Dias } \\
\cline { 2 - 5 } & \multicolumn{1}{|c|}{$\mathbf{N}$} & \multicolumn{1}{c|}{$\%$} & \multicolumn{1}{c|}{ N } & \multicolumn{1}{c|}{$\%$} \\
\hline Campanha & 421 & 44,9 & 808 & 36,3 \\
\hline Assuntos pessoais & 97 & 10,4 & 247 & 11,1 \\
\hline Propostas de políticas públicas & 229 & 24,4 & 364 & 16,3 \\
\hline Apoio & 13 & 1,4 & 175 & 7,9 \\
\hline Ético-moral & 50 & 5,3 & 64 & 2,9 \\
\hline Outros & 50 & 5,3 & 197 & 8,8 \\
\hline Novas mídias & 18 & 1,9 & 45 & 2,0 \\
\hline Conversa e agradecimento & 59 & 6,3 & 328 & 14,7 \\
\hline Total & 937 & 100,0 & 2.228 & 100,0 \\
\hline
\end{tabular}

Fonte: Autores

Sobre as divergências entre eles, observa-se que, enquanto Osmar Dias apresenta $14,7 \%$ dos seus posts categorizados em "Conversa e agradecimento", apenas $6,3 \%$ do conteúdo do Beto Richa encaixa-se nesta categoria. Durante a análise, percebeu-se que esse tipo de postagem aparece em mensagens como a seguinte, publicada pelo candidato do PDT no dia $1^{\circ}$ de julho: "Agradeço às milhares de manifestações de apoio e de força. Vamos mostrar que temos mais amor pelo Paraná. Juntos!". Há também uma diferença entre os dois candidatos ao tratar de políticas públicas, que mesmo sendo um dos temas principais de ambos, está mais concentrado nos posts do Beto Richa.

Outro destaque é para a diferença quanto à categoria apoio, que apresenta 7,9\% dos posts de Osmar Dias e apenas $1,4 \%$ para Beto Richa. Isso significa que o candidato do PDT usava mais a ferramenta para pedir apoio e voto dos eleitores. Mas, em resumo, mesmo destacando essas diferenças, em ambos predomina o conteúdo informativo de agenda diária e apresentação de políticas públicas. No entanto, notam-se algumas diferenças quanto à presença dos temas ao longo do tempo, se comparados os posts de Beto e Osmar (Gráfico 4).

Percebe-se, de acordo com o gráfico de Beto Richa, que os temas oscilam durante os meses de campanha. No entanto, durante todo o período, os posts sobre campanha são os que se mantêm mais estáveis, mas com tendência de crescimento, principalmente em função do aumento total das postagens do candidato. Destaca-se um maior volume na postagem de assuntos pessoais a partir da nona semana, seguindo até a décima primeira. Outra mudança importante é o crescimento da apresentação de propostas de políticas públicas, com a proximidade da data das eleições, o que acontece de forma inversa para o caso de Osmar Dias. Percebe-se ainda que mensagens de apoio aparecem centralizadas em determinados momentos e foram pouco presentes na campanha on-line.

Diferentemente do que ocorreu com seu adversário, Osmar Dias apresenta queda na quantidade de postagem sobre propostas de políticas públicas com a aproximação das eleições. Percebe-se, portanto, que enquanto políticas públicas se destacam na campanha de Beto Richa, essa relação se dá de forma oposta para Osmar Dias, que apresenta queda com relação a esse tema se comparadas as primeiras semanas com as últimas. Nota-se ainda que, ao passo que todos os temas caem em quantidade de posts, há alguns picos de postagem para textos de apoio e também com conversas com os eleitores. São textos de apoio, dizendo, por exemplo, que cresce o apoio no interior do estado, como mostra o texto “@Osmar_Dias12 Sua campanha está crescendo kda dia aqui no sul do estado, União da Vitória, General Carneiro, Bituruna, Pinhão etc." (30/agosto - Osmar Dias), ou também com postagens de eleitores dizendo que votarão no candidato.

Para complementar a análise, os dados apresentados a seguir indicam se os temas se relacionam com determinados tipos de postagens (publicação, retweet e respostas). Isso ajuda a explicar relações entre os gráficos que acompanham a distribuição dos temas e dos tipos de postagens ao longo da campanha. A Tabela 


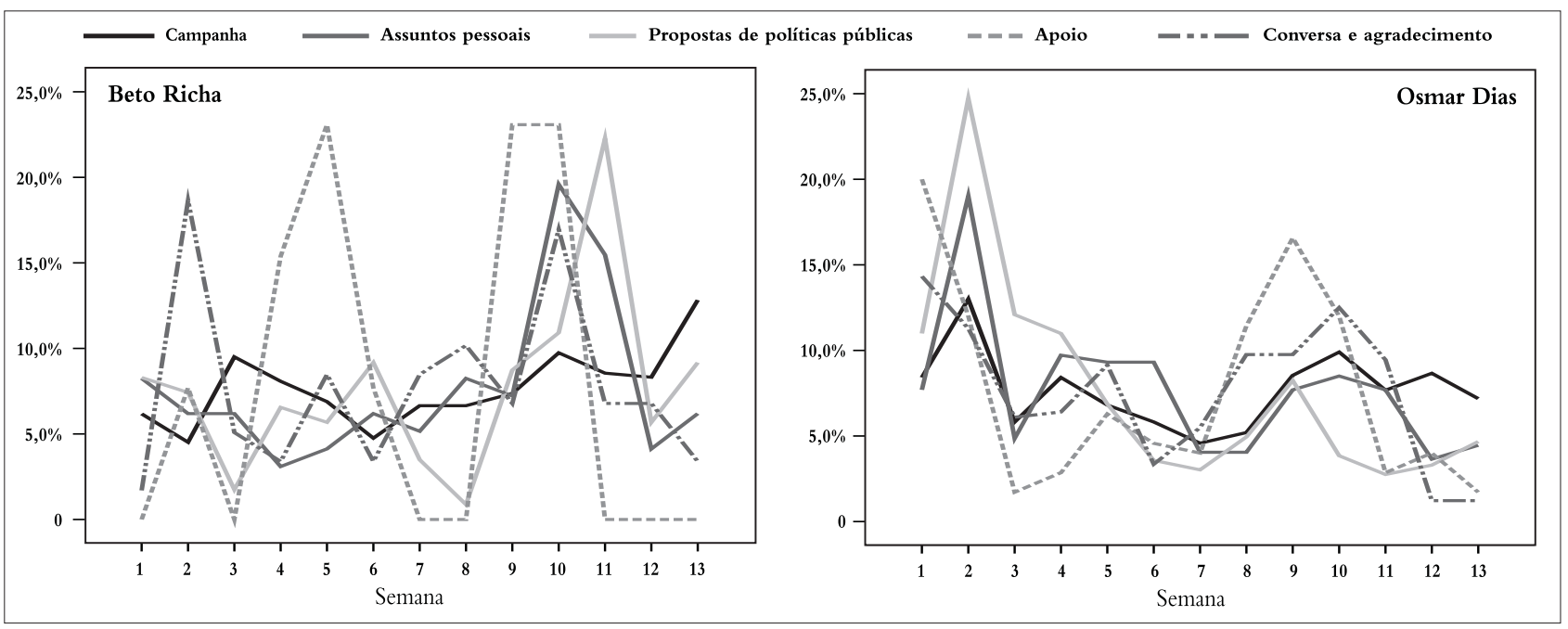

Gráfico 4 - Distribuição dos temas das postagens de Beto Richa e Osmar Dias Fonte: Autores

Tabela 4 - Distribuição dos temas por tipo de post de Beto Richa

\begin{tabular}{|c|c|c|c|c|c|c|c|c|}
\hline Beto Richa & Campanha & $\begin{array}{c}\text { Assuntos } \\
\text { pessoais }\end{array}$ & $\begin{array}{c}\text { Propostas } \\
\text { políticas }\end{array}$ & Apoio & Ético-moral & Outros & $\begin{array}{l}\text { Novas } \\
\text { mídias }\end{array}$ & $\begin{array}{c}\text { Conversa e } \\
\text { agradecimento }\end{array}$ \\
\hline Publicação & $\begin{array}{r}60,8 \% \\
7,5\end{array}$ & $\begin{array}{r}19,6 \% \\
-3\end{array}$ & $\begin{array}{r}18,8 \% \\
-4,8\end{array}$ & $\begin{array}{r}15,4 \% \\
-1,3\end{array}$ & $\begin{array}{r}30,0 \% \\
-0,9\end{array}$ & $\begin{array}{r}22,0 \% \\
-1,9\end{array}$ & $\begin{array}{r}38,9 \% \\
0\end{array}$ & $\begin{array}{r}10,2 \% \\
-3,5\end{array}$ \\
\hline Resposta & $\begin{array}{r}31,4 \% \\
-6,9\end{array}$ & $\begin{array}{r}76,3 \% \\
2,6\end{array}$ & $\begin{array}{r}79,5 \% \\
4,6\end{array}$ & $\begin{array}{r}76,9 \% \\
1\end{array}$ & $\begin{array}{r}68,0 \% \\
1,1\end{array}$ & $\begin{array}{r}72,0 \% \\
1,4\end{array}$ & $\begin{array}{r}55,6 \% \\
0\end{array}$ & $\begin{array}{r}89,8 \% \\
3,4\end{array}$ \\
\hline Retweet & $\begin{array}{r}7,8 \% \\
2,6\end{array}$ & $\begin{array}{r}4,1 \% \\
-0,4\end{array}$ & $\begin{array}{r}1,7 \% \\
-2,2\end{array}$ & $\begin{array}{r}7,7 \% \\
0,4\end{array}$ & $\begin{array}{r}2,0 \% \\
-1\end{array}$ & $\begin{array}{r}6,0 \% \\
0,3\end{array}$ & $\begin{array}{r}5,6 \% \\
0,1\end{array}$ & $\begin{array}{r}0,0 \% \\
-1,7\end{array}$ \\
\hline Total & $100,00 \%$ & $100,00 \%$ & $100,00 \%$ & $100,00 \%$ & $100,00 \%$ & $100,00 \%$ & $100,00 \%$ & $100,00 \%$ \\
\hline
\end{tabular}

Fonte: Autores

4 mostra a distribuição dos percentuais e os resíduos padronizados que, apesar de se trabalhar neste estudo com números absolutos e não com amostragem, servem param mostrar a variação conjunta entre duas categorias de cada uma das variáveis. Como o intervalo de confiança é de $95 \%$, resíduos acima ou abaixo de $+-1,96$ são considerados significativos, portanto, indicando concentração de determinado tema em um tipo de publicação.

No caso de Beto Richa, destaca-se que o assunto "Campanha" é recorrente em publicações do candidato, assim como nas mensagens de terceiros que são replicadas por ele. Já os assuntos pessoais tendem a estar nas respostas, da mesma forma que as propostas de políticas e conversa e agradecimento. Isso significa que, enquanto assuntos de agenda estão majoritariamente em mensagens escritas por Beto, as postagens sobre políticas estão nas respostas dadas aos eleitores. Dessa forma, Beto tem mais posts caracterizados como respostas e ao mesmo tempo também tem mais mensagens com o tema políticas públicas.

Essa informação mostra ainda que o candidato só trata de política pública porque é questionado pelos eleitores, já que o assunto é pouco recorrente (18\%) em mensagens próprias e também em republicação $(1,7 \%)$. Sendo assim, caso os eleitores não perguntassem sobre o tema, possivelmente ele estaria ausente do discurso do candidato nas redes sociais. Isso mostra, portanto, como a lógica das redes sociais depende não apenas do candidato, mas também dos eleitores que estão mobilizados na disputa e se interessam em saber sobre temas sociais e de interesse público por meio desse canal informativo.

Percebeu-se ainda a ausência do tema campanha em respostas, pois o candidato optava em divulgar as informações de campanha para todos os seus seguidores. "Conversa e agradecimento" também não aparece na publicação, pois, sempre que o candidato usa esse tipo de estratégia, ele faz contato diretamente com o seguidor que havia lhe escrito anteriormente. Alguns desses dados se repetem nas postagens de Osmar Dias, como a Tabela 5 mostra a seguir. No entanto, aqui os resíduos são mais altos, o que significa relações mais fortes entre as categorias das duas variáveis.

Da mesma forma que na relação mostrada para o outro candidato, no caso de Osmar Dias o tema "Campanha" também tende a estar em publicações próprias $(62,4 \%)$, estando, no entanto, ausente das 
respostas, pois somente $17,6 \%$ de posts relacionados a essa questão foram encontrados nas respostas. Propostas de políticas, questões ligadas a assuntos pessoais e manifestações de agradecimento são recorrentes nas respostas dadas pelo candidato, sendo que assuntos relacionados a campanha e apoio não tendem a aparecerem nesse tipo de postagem, pois os resíduos apontam para uma relação negativa. Assuntos pessoais não aparecem em publicações próprias nem em retweets, o que demonstra um esforço em evitar a divulgação de questões mais 'privadas' junto aos seguidores. Destaca-se que propostas de políticas públicas também não têm relação com retweets, da mesma forma que agradecimentos, ficando restritos apenas às respostas, da mesma forma que ocorre com Beto Richa.

A maior diferença entre os dois candidatos está na relação dos temas com o mecanismo de replicar mensagens de outras pessoas. Enquanto para Beto destacavam-se temas de campanha, para Osmar a relação de retweet centrava-se em apoio, ou seja, há uma tendência de este assunto aparecer veiculado em postagens feitas por outras pessoas e apenas replicadas pelo candidato. Elas servem para mostrar fatos positivos e apoio a sua candidatura, como mostra o exemplo: “É isso ai@botecoterapia vamos eleger nosso governador,@Osmar_Dias" (31/agosto - Osmar
Dias). Dessa forma, os dados das duas últimas tabelas mostraram tendências muito próximas entre os candidatos. Para continuar, a Tabela 6 apresenta os tipos de discurso usados pelos dois candidatos.

Ressalta-se que poderia haver mais de um tipo de discurso presente numa mesma postagem. Além disso, percebe-se que houve uma padronização entre os candidatos. O que mais apareceu foi publicação de notícias, sem outras ênfases dos candidatos, tal como o exemplo a seguir: "Os materiais de campanha podem ser encontrados nos comitês. Se estiver com dificuldades de encontrá-los me avise, ok?" (25/agosto - Osmar Dias). Isso ocorre mais nos posts de Osmar Dias, com 49,1\% em comparação aos 31,1\% para Beto. Em contrapartida, Beto apresenta um discurso mais pró-ativo na apresentação de ações futuras do que Osmar, como mostra o exemplo: “Olá@barracadomarcao vamos promover a formalização da economia com inovadoras e compartilhadas de fomento e incentivo fiscal" (5/julho - Beto Richa). Os percentuais são próximos para "Agradecimento", embora haja diferenças quanto à presença do discurso de vitória, que se destaca nas postagens de Beto.

Outras diferenças são notadas em função dos partidos e das posições que os candidatos ocupam. Destaca-se para Beto Richa a presença do discurso de

Tabela 5 - Distribuição dos temas por tipo de post de Osmar Dias

\begin{tabular}{|l|r|r|r|r|r|r|r|r|}
\hline \multicolumn{1}{|c|}{ Osmar Dias } & Campanha & $\begin{array}{c}\text { Assuntos } \\
\text { pessoais }\end{array}$ & $\begin{array}{c}\text { Propostas } \\
\text { políticas }\end{array}$ & \multicolumn{1}{c|}{ Apoio } & Ético moral & Outros & $\begin{array}{c}\text { Novas } \\
\text { mídias }\end{array}$ & $\begin{array}{c}\text { Conversa } \\
\text { agradecimento }\end{array}$ \\
\hline \multirow{2}{*}{ Publicação } & $62,4 \%$ & $18,6 \%$ & $38,2 \%$ & $22,9 \%$ & $50,0 \%$ & $42,6 \%$ & $53,3 \%$ & $5,8 \%$ \\
\hline \multirow{2}{*}{ Resposta } & 10,1 & $-5,3$ & $-0,5$ & $-3,6$ & 1,3 & 0,6 & 1,4 & $-9,8$ \\
\hline \multirow{2}{*}{ Retweet } & $17,6 \%$ & $67,6 \%$ & $49,7 \%$ & $18,9 \%$ & $28,1 \%$ & $33,0 \%$ & $26,7 \%$ & $88,4 \%$ \\
& $-10,3$ & 6,6 & 2,7 & $-4,5$ & $-1,6$ & $-1,7$ & $-1,5$ & 13,5 \\
\hline & $20,0 \%$ & $13,8 \%$ & $12,1 \%$ & $58,3 \%$ & $21,9 \%$ & $24,4 \%$ & $20,0 \%$ & $5,8 \%$ \\
& 0,4 & $-2,0$ & $-3,2$ & 11,7 & 0,5 & 1,6 & 0,1 & $-5,6$ \\
\hline
\end{tabular}

Fonte: Autores

Tabela 6 - Tipos de discurso usados pelos candidatos nas postagens

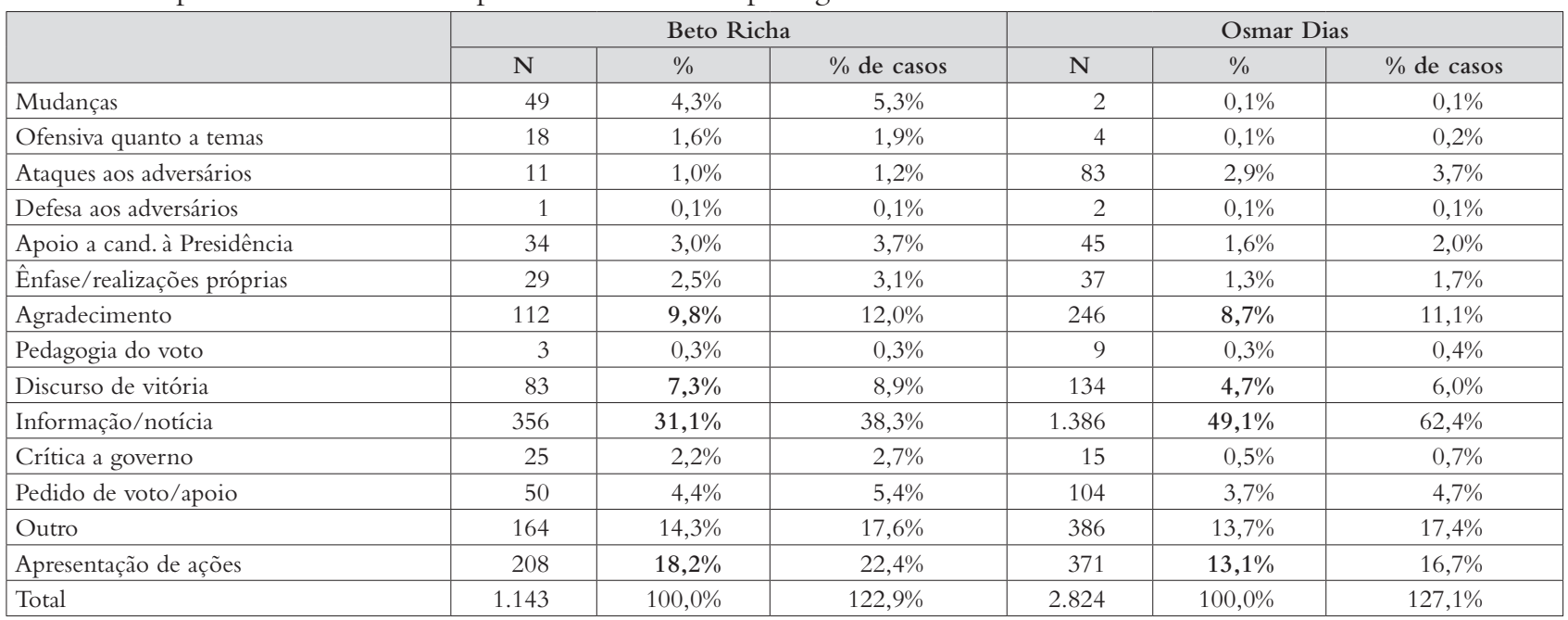

Fonte: Autores 
mudança ("Vamos mudar isto@gui_boer O Paraná e os paranaenses merecem respeito e ter de volta em investimentos sociais os impostos que mandamos" 21/setembro) e também crítica ao governo ("Não é só Londrina@gui_boer parece que todo o Paraná ficou esquecido e durante 8 anos só entrou pela porta dos fundos em Brasília" - 21/setembro). As mensagens de mudança se referem à entrada do PSDB no governo do estado, administrado nos últimos oito anos por Roberto Requião (PMDB), pertencente nas eleições de 2010 à coligação com o PDT de Osmar Dias. E a diferença mais significativa para Osmar Dias é o ataque aos seus adversários, em 2,9\% das postagens.

O Gráfico 5 mostra a distribuição dos principais discursos ao longo do período para Beto Richa. A distribuição fica estável até a nona semana de campanha, os quais não passam de 15\%. Mas, a partir do último mês, passa a se destacar mais nas postagens os agradecimentos, as ações de políticas públicas e o discurso de vitória, que na última semana alcança quase $50 \%$ dos posts do candidato (mais de 40 postagens). Percebe-se com esta análise uma maior estabilidade no uso dos discursos do que do candidato do PDT.

Os dados apontados indicam que os discursos de Osmar oscilaram com o tempo. Da mesma forma que Beto, o discurso de vitória cresce no final da campanha, embora sempre estivesse mais presente desde o início. Ele aumenta no momento em que Osmar sobe nas pesquisas e fica mais próximo de Beto $\mathrm{Ri}$ cha. Também se mantém, como ocorre com Beto, o crescimento de manifestações de agradecimento mais ao final da campanha, a partir da oitava semana. Mas, ao contrário de Beto, o discurso de ação caiu ao longo do tempo, pois no começo esteve em $26 \%$ das postagens, mas terminou em menos de $6 \%$. Outra diferença é que, com o passar do tempo, também caiu a quantidade de informação de campanha, sendo que Beto Richa manteve percentuais próximos durante todo o tempo. Esses dados mostraram que, embora tenha havido coincidências quanto aos discursos mais usados pelos candidatos, a forma com que eles apareceram ao longo do tempo foi bem diferente entre os dois, principalmente no que diz respeito à apresentação de ações e notícias de campanha.

Para completar a análise, observou-se em que medida as redes sociais permitem ampliar o debate público entre candidatos e eleitores em termos políticos tradicionais. No caso, parte-se da verificação da citação de partido e coligação nas postagens, com o objetivo de identificar se o perfil pessoal dos candidatos também faz campanha, mencionando o partido do qual fazem parte ou a coligação, ou seja, se eles agem de maneira partidarizada.

Tabela 7 - Presença de partido e coligação nas postagens

\begin{tabular}{|c|c|c|c|c|}
\hline \multirow{2}{*}{$\begin{array}{c}\text { Presença Partidos } \\
\text { Coligação }\end{array}$} & \multicolumn{2}{|c|}{ Beto Richa } & \multicolumn{2}{c|}{ Osmar Dias } \\
\cline { 2 - 5 } & N & $\%$ & N & $\%$ \\
\hline Não & 819 & 87,4 & 2096 & 94,1 \\
\hline Sim & 118 & 12,6 & 132 & 5,9 \\
\hline
\end{tabular}

Fonte: Autores

Esse tipo de ação ocorre mais nas postagens de Beto Richa, com 12,6\%, e em apenas 5,9\% das mensagens de Osmar Dias. Geralmente esse tipo de campanha ocorria da seguinte forma, como mostram os exemplos a seguir: "Olá @EloirMartins conto com a força de todos.Vamos replicar as ideias e propostas do Novo Paraná para ganharmos, juntos, no próximo dia"(21/setembro - Beto Richa) e "O PDT é um partido plural e mantém em seus quadros lideranças de todas as correntes" (12/julho - Osmar Dias). Mas como esses casos apareceram de forma residual nas postagens, conclui-se que, nesse espaço de campanha, os candidatos não agem de maneira partidarizada,

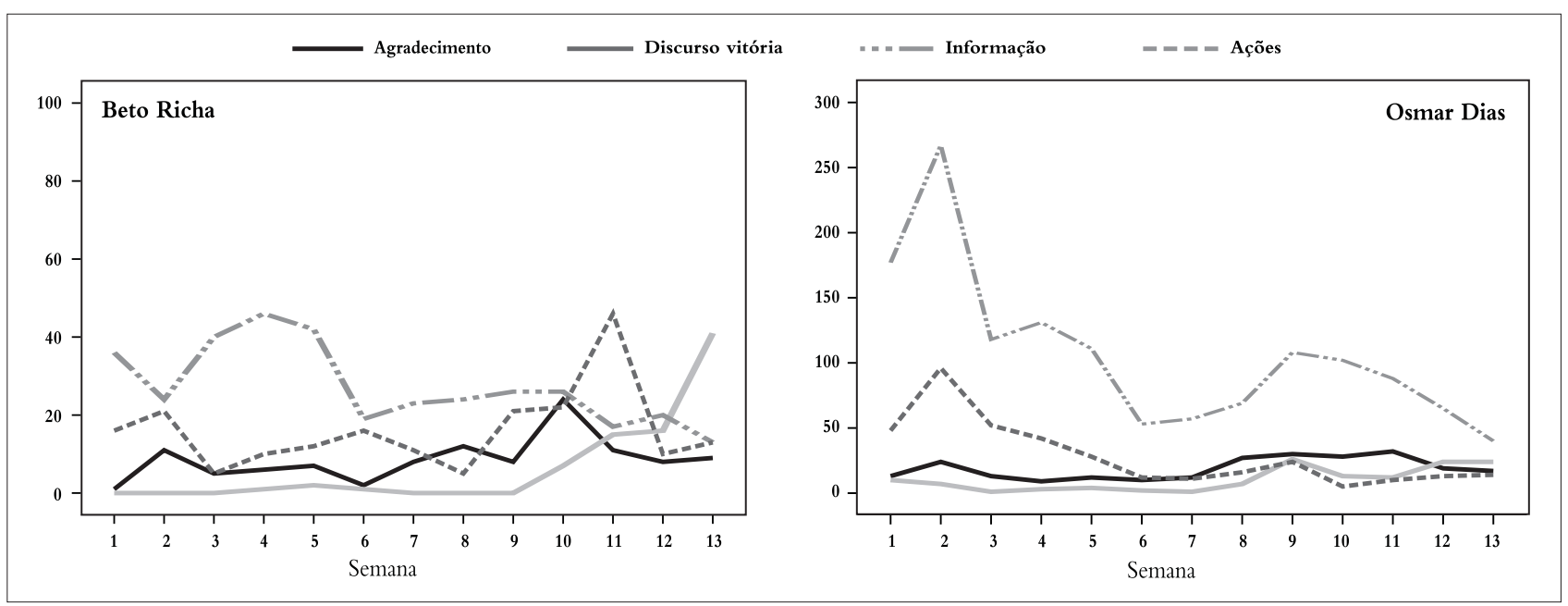

Gráfico 5 - Distribuição dos tipos de discurso de Beto Richa (esq.) e Osmar Dias (dir.) 
sendo esta uma ferramenta mais personalista, focada nas ações do candidato apenas.

\section{Considerações finais}

$\mathrm{O}$ artigo apresentou uma proposta aplicada de análise sobre o uso que os candidatos ao governo do Paraná - Osmar Dias e Beto Richa - fizeram do Twitter durante o período eleitoral de 2010. A pesquisa identificou que eles fizeram uso mais intensivo dessa ferramenta se comparado a outras disputas, como para presidente, por exemplo. Uma possível explicação para isso pode ter sido o acirramento da disputa entre os candidatos no estado. As principais tendências percebidas quanto ao uso do Twitter foram o foco informativo, sobre campanha ou propostas de políticas; o uso efetivo para manter contato com os eleitores, devido à presença de muitas respostas entre as postagens; a personalização da ferramenta, já que eles não agem de maneira partidarizada, e a ausência de ataques a adversários.

No entanto, ficaram perceptíveis algumas diferenças entre Beto e Osmar. A primeira delas diz respeito à frequência de uso da ferramenta, com destaque para Osmar Dias (PDT). Além disso, percebeu-se alteração quando ao momento de maior e menor uso. Há uma inversão entre os candidatos, se comparadas as primeiras e últimas semanas, pois Beto postou mais no final da campanha do que no início, ao contrário de Osmar. Uma possível motivação para essa diferença é que, principalmente no início da campanha, a liderança foi de Beto Richa, não necessitando de uma mobilização on-line, diferente do que ocorreu mais ao final, quando seu adversário sobe nas pesquisas de intenção de voto e torna-se necessário mobilizar o eleitorado. Osmar usou mais o Twitter no momento em que precisou de apoio da militância, deixando-o de lado quando subiu nas pesquisas de intenção de voto. Dessa forma, pode-se dizer que os candidatos buscam as redes sociais nos momentos em que precisam do ativismo dos eleitores.

Além disso, percebem-se diferenças também quanto à distribuição dos temas ao longo do tempo, assim como das estratégias discursivas utilizadas. Sobre os temas, as maiores alterações estão relacionadas à inversão de campanha e a propostas de políticas para os dois candidatos. Enquanto políticas públicas se destacam no final da campanha de Beto Richa, na campanha de Osmar Dias o tema apresenta queda ao longo do tempo. Quanto às estratégias, a maior diferença esteve no final da campanha, quando crescem os percentuais de "discurso de vitória" de Beto Richa, sendo que, para Osmar, percebe-se a presença dessa estratégia desde o início do período. Além disso, os principais discursos de Beto mantiveram-se estáveis ao longo dos quatro meses, diferentemente de Osmar, que apresentou bastante instabilidade.

De maneira geral, a ferramenta atende o seu objetivo no cenário das disputas políticas, que é oferecer mais um espaço de campanha aos candidatos e principalmente proporcionar maior aproximação com os eleitores, que seria uma forma mais parecida com a 'relação face a face' ainda muito presente em campanhas menores, que ainda não alcançaram esta etapa de profissionalização (Norris, 2001). Com a novidade da internet nessa fase mais avançada de disputa apresentada por Norris (2001), é possível se apropriar dessa relação de proximidade com essa parcela da população que usa a internet com frequência e tem certo interesse por política, já que muitos escrevem e mantêm contato com os candidatos. Outro 'achado' da análise é a importância que os eleitores, militantes e seguidores têm no estabelecimento dos padrões do uso do Twitter. As análises feitas aqui mostraram, por exemplo, que os candidatos só discutem temas de políticas públicas quando os eleitores os questionam. Portanto, estes últimos mantêm posições importantes na relação, pois instigam os candidatos a debaterem temas de interesse público e principalmente a manterem-se em constante relação com o eleitorado ao longo da campanha. 


\title{
Referências bibliográficas
}

AGGIO, C. As campanhas políticas no Twitter: Uma análise do padrão de comunicação política dos três principais candidatos à presidência do Brasil em 2010. Anais do IV Encontro da Compolítica, Rio de Janeiro, UERF, 2011.

ALDÉ, A. Jornalistas e internet: a rede como fonte de informação política. In: Iv Encontro dos Núcleos de Pesquisa da Intercom, 2004.

ANDUIZA, E. Internet, campañas electorales y ciudadanos: el estado de la cuestión. Quaderns del CAC, n 33, 2009.

COLEMAN, S. Can the new media invigorate democracy? The Political Quartely Publishing, 1999.

COUTINHO, M; SAFATLE, V. A internet e as eleições municipais em 2008: o uso dos sítios eletrônicos de comunidades na eleição paulistana. Sociologia Política, v.17, 2009. DAHLGREN, P. The internet and the democratization of civic culture. Political Communication, v. 17, p. 335-340, 2000.

GIBSON, R. K.; WARD, S. A proposed methodology for studying the function and effectiveness of party and candidate web sites. Social Science Computer Review, Durham, no 18, p.301-319, 2000.

GOMES, W. Internet e participação política em sociedades democráticas. Revista Famecos, no 2, 2005.

IASULAITIS, S. Internet e propaganda política no Brasil: limites e possibilidades. Estudos de Sociologia (São Paulo), v. 23, p. 153-172, 2007.

LEMOS, A. Nova esfera conversacional. In: DIMAS, A; KÜNSCH, D.A; SILVEIRA, S.A., et al. Esfera pública, redes e jornalismo. Rio de Janeiro: Ed. E-Papers, 2009.

LEVY, P. Cibercultura. Tradução de Carlos Irineu da Costa. São Paulo: Editora 34, 1999.

MONTERO, M. D. E-movilización y participación políticas en las campañas electorales de Ségolène Royal (2007) y Barack Obama (2008). Quaderns del CAC, $\mathrm{n}^{\circ}$ 33, 2009.

NICOLÁS, M. A.; FRANÇA, S. T.; BRAGA, S. S. Mecanismos de participação nos websites dos candidatos a prefeito nas eleições de 2008 no Brasil. In: $7^{\circ}$ Encontro da Abcp/Associação Brasileira de Ciência Política, 2010, Recife.

NORRIS, P. Digital divide: Civic engagement, information poverty, and the Internet worldwide. Cambridge: Cambridge University Press, 2001.

Preaching to the converted? Pluralism, participation and party websites. Party Politics, 9(1): 21-45, 2003.

Political communications and democratic politics. In: BARTLE, J; GRIFFITHS, D. Political communication transformed: from Morrison to Mandelson. Basingstoke: Macmillan, 2004.

ORIHUELA. Twitter y el boom del microblogging. In: Perspectivas del mundo de la comunicación. Facultad de Comunicación, Universidad de Navarra, 2007.

RECUERO, R. Redes sociais na internet. Porto Alegre: Sulina, 2009.

SPYER, J. Tudo o que você precisa saber sobre o Twitter. 2009. Disponível em: www.talk2.com.br. Acesso em: 18/6/2011. STANLEY, J. W.; WEARE, C. The effects of Internet use on political participation: evidence from an agency on-line discussion forum. DG.O, 2003.

TURIERA-PUIGBÒ, T. ¿Qué está cambiando el uso de internet en la manera de hacer y comunicar la acción política? Quaderns del CAC, n 33, 2009.

VACCARI, C. Italian Parties' Websites in the 2006 Elections. European Journal of Communication, 2008.

\section{Social networks in 2010 election campaign: analysis of Parana governor candidates' Twitter postings}

\begin{abstract}
This article discusses the use of social networks as an election campaign tool, having as object of analysis the content posted on Twitter by the two major Parana governor candidates - Beto Richa (PSDB) and Osmar Dias (PDT) - from July 1th to October 3th, 2010. Through some characteristics (number of postings, themes, speech, types, use of links, presence of opponents etc.), the aim was to identify how the candidates used this technology tool to contact voters. The quantitative content analysis method was used. It enabled comparing the data obtained from both candidates, which together totalized 3.165 postings, and made it possible to identify the candidates' different ways of using Twitter.
\end{abstract}

Key words: social networks, election campaign, Twitter, election. 


\title{
Las redes sociales en la campaña electoral en 2010: el contenido publicado por los candidatos a gobernador de Paraná en Twitter
}

\begin{abstract}
Resumen
Este artículo tiene como objetivo discutir el uso de las redes sociales como herramienta de campaña, con el objeto de análisis el contenido publicado en Twitter por los dos principales candidatos a gobernador de Paraná - Beto Richa (PSDB) y Osmar Dias (PDT) - desde 1 de julio hasta 3 de outubro de 2010. Por medio de algunas de las características (número de mensajes, el discurso, los temas, tipo de mensajes, el uso de links, la presencia de los opositores etc.), identificar cómo los dos candidatos utilizaron la herramienta para relacionarse con los votantes. La metodología utilizada para desarrollar el artículo es el análisis cuantitativo de contenido que también permite la comparación de datos entre los dos candidatos, que en conjunto escribieron 3.165 mensajes en el Twitter. Esto hace posible identificar las diferencias en el uso de twitter entre los dos principales candidatos a gobernador de Paraná en 2010.
\end{abstract}

Palabras-clave: redes sociales, campaña, Twitter, elecciones.

Data de recebimento do artigo: 10/11/2011

Data de aprovação do artigo: 29/01/2012 